\title{
Commentary
}

\section{Science, Nature and the Ethical Pursuit of Happiness: A Discussion ${ }^{1}$}

\author{
Meera Baindur*
}

\section{Abstract}

Most philosophical engagements with science have been focused on the methods of science, epistemological concerns, nature of scientific methods or natural laws. New disciplines such as Science Studies and History of science have emerged from these inquiries and address any concerns on the relationship of science to society and knowledge. In this essay, the attempt is to clarify how scientific thought is not excluded from the moral domain. While a scientific fact itself cannot be subjected to moral or aesthetic judgement, since it is only, the aims and objects of scientific research can be a concern for philosophical ethics. Particularly the development of applied sciences that are focused on the exploitation of the natural world and unsustainable practices must become not only subject to moral supervision but also must be answerable to society and humanitarian interests. An analysis of the purpose of science and philosophy posits what should be the areas of science that should be subject to ethical judgements.

Keywords: Pursuit of Knowledge, Objectivity, Morality, Ethics of Science

\footnotetext{
* Manipal University, Jaipur, India; meera.baindur@gmail.com
} 
1 This is a modification of the Convener address delivered at the XLIII Indian Social Science Congress in Jan 17-21, 2020 at Bengaluru Central University, Philosophy Research Committee

\section{Introduction}

When articulated simply, the aims and objectives of science are the same as what scientists 'do'. A better way to understand science is to define the function of scientific knowledge; Science is factual information and this factual knowledge is supposed to explain nature and its processes from a naturalistic perspective as opposed to a supernatural perspective. The idea is also to posit that the 'truth' of scientific fact is to be the criteria of judging 'good science' and science that is corrupted by unethical practices of the scientists cannot be good science at all. So, a cursory survey of scholarship related to ethics and science is about the integrity of science or the professional ethics of doing science, the robustness of research design, the rigours of a scientific method - all of which are concerned with proper research ethics, or in case of medical sciences, concerned with bio-ethics.

So, within the domain of disciplines that are called natural sciences, moral and aesthetic judgment do not apply to science. The critique of gender or unequal representation of certain castes or communities in scientific institutions do not concern the discipline of science itself but concern the politics of scientific policy and social factors that are considered exterior to the results of science. In his book What is Science, Sarukkai (2012, pp. 23-24) suggests that science has a unique perspective of looking at nature and two main presuppositions that help it observe and catalogue nature. He points out that first, for science nature is uniform and has certain stability that allows prediction and a search for universal laws. The second presupposition of science is that science has no agency of its own. It is also inanimate and mute and sterile to our investigations. To observe nature, Sarukkai (2012, p. 24) suggests that humans must consider themselves outside of it. These ideas of nature are essential to the very existence of science itself, he claims. 
These ideas about science seem to be inherited from a time of history when science was in its nascent state as a part of human endeavour. Carolyn Merchant (2005, p. 61) points out the dominant mechanistic paradigm of science has resulted in the death of nature:

The mechanistic worldview continues today as the legitimating ideology of industrial capitalism and its inherent ethic of the domination of nature. Mechanistic thinking and industrial capitalism lie at the root of many of the environmental problems.

It is clear from scholarly discussions that since science explains facts about the world around us, it is sometimes referred to as a kind of "objective knowledge," as it does not take on other perspectives of judgment such as aesthetic or moral which are believed to be subjective and not factual. The work of philosophy on the other hand is this precise area that science excludes. Philosophy is a discipline that works in thinking about the moral and aesthetic dimensions of activities. So rather than looking at philosophy as a discipline that is opposed to science or something that is an archaic form of scientific thinking, one should take the position that philosophy and science are complementary in the kinds of descriptions they produce about the world. The criteria for good philosophy and good science would be the same while the kind of knowledge they produce would not be the same, rather, they must not be the same. So, it can be posited that while both science and philosophy attempt to seek truths about the world, the one primary difference is that Philosophy is free to do what science excludes from its domain of explanations that is, to have opinions about knowledge and its production.

\section{Aims of Science}

The main concepts that one could analyse include ethical perspectives about the aims of science and the domains of knowledge of science and philosophy in the contemporary world. Using the method of conceptual analysis, one could explore the questions science has been asking since its growth in the last few 
centuries. Three questions are interesting to examine within the context of the philosophical qualities of science and its study of nature. These queries do not pertain to the differences in the ontological or metaphysical question of what nature is but instead examines the aims of science and methods of science. In other words, the evaluation is about not what science studies in nature but about how science studies nature, and as a subject that attempts to seek the truth, we can ask is science ethically true to its purpose'. Is science factual enough, is it 'good science'?

To begin the query, one must ask what is the purpose of science? Is it a pursuit of happiness or pursuit of knowledge? If it is knowledge for knowledge's sake, then why a particular type of knowledge? These are questions that people must answer for themselves when they're doing anything. One might ask why someone wants to earn money in the stock market rather than working in a regular job. Or ask why a student prefers to study philosophy rather than psychology?

So, when one asks "why do we do science?" it is a bad question. One cannot simply ask these questions of the existence of disciplines. But one can ask why is science doing the things it does that are not aligned with the purpose of science? In this regard, one can posit that there are two kinds of purposiveness to doing science.

One could say the first aim of science is the pursuit of knowledge about nature. A scientist claims this is a domain of factual knowledge about nature and its workings and how these processes in nature take place. And science is to determine what kind of things are present in nature and around us, and how they interact with each other. This factual method is subjected to the methods of scientific falsifiability, experimentation, scientific explanation, and so on. A strict community of peers is established to make sure the knowledge is accurate, updated and always moved towards better and valid explanations. The second reason may be considered not a true aim of science, but often in the real world, this explanation is given as a reason for doing science. Science makes advances in knowledge which help society. Scientific knowledge can lead to the 
progress of humankind through technical advances and medical benefits.

While there is no particular reason that science should benefit humankind beyond the advancement of knowledge, there is always a hidden agenda that seems to imply that science is not just knowledge for knowledge's sake. The discourse of science in society is that science is useful knowledge, even the facts about the temperatures at which water boils or freezes allow us to sterilize baby feeding bottles or make ice cubes for our drinks. The author remembers looking at the pressure cooker and thinking "Boyle's law, Boyle's law" after a lecture on volume, pressure, and temperature.

It is, however important to move away from these basic simple scientific facts as the ideal representation of scientific knowledge, these facts that are now very much older discoveries, though these are still taught as foundations and concepts in school. Particularly after most of the basic scientific facts about the world of nature have been investigated, the scientific knowledge that is produced today is no longer about simple explanations. These facts are altered, subjected to factors of change and a long series of information is gathered that tests as many scenarios as possible. This knowledge of how things work in nature is applied to invent things and contribute to society in many ways. Though it is the job of technology to make these discoveries of science tenable and usable in the real world, one cannot deny that the importance of the origins and foundational principles of these discoveries are in the field of natural sciences even before they impact something in the world. Faraday discovered induction as early as $1831,{ }^{\text {i but it was }}$ only in the early 20 century that this heat itself was posited as a useful way for melting steel or heating substances.

It seems to be somewhat true that the primary purpose of scientific knowledge and fact seeking need not be ethically questioned. One cannot make an ethical opinion about the discovery of the induction itself or the tracking of the orbit of a new planet. If all knowledge was judged from its utilitarian value very few human endeavours will pass the test of usefulness. 
However, the second dimension of scientific knowledge would become important in the questions of human lifestyle, comfort, efficiency that are linked to the pursuit of human happiness all of which come under the domain of moral philosophy.

Sayer (2011) claims that "A deeper form of ethical reflection involves the contestation of dominant cultural values and institutions. Particularly in complex, divided and plural societies, different conceptions of virtues and the nature of the good life vie with one another" (p. 172).

The idea is not to discuss the personal happiness of a scientist who is discovering facts of nature but to highlight the collective happiness of humankind on the whole - a 'social pursuit of happiness' for human society that has become important to discuss in the modern world. This means that whenever science is used for a collective purpose, not just satisfying the curiosity of a scientist, it must come under ethical scrutiny.

People have also questioned these projects of science in terms of not the actual purposiveness but sometimes the questions asked of these projects are based on economic factors. Is it possible for one to invest huge amounts of money in these factual questions when there are other humanitarian requirements for the resources?

For instance, a question could be asked 'why clone'? One could enquire if genetic engineering should focus on a project to clone a whole human being? On the other hand, is it different when we research how to clone a pancreas for a diabetic patient? Are there ethical gradings of scientific aims possible? Similar questions were raised after the use of the atomic bomb and these questions have not been resolved both for philosophy and science. This essay does not claim to have answers to these questions here but highlights that these are some of the things that philosophers and scientists must think about together.

\section{Nature and Science}

Merchant (2005) points out that the scientific project works through the domination of nature: 
Both order and power are integral components of the mechanical view of nature. Both the need for a new social and intellectual order and new values of human and machine power, combined with older intellectual traditions, went into the restructuring of reality around the metaphor of the machine. The new metaphor reintegrated the disparate elements of the self, society, and the cosmos torn asunder by the Protestant Reformation, the rise of commercial capitalism, and the early discoveries of the new science.

The questions about the paradigms of science itself, its disregard for nature as an important part of humankind's wellbeing and flourishing becomes imperative to foreground as a problematic.

By now it is possible to start seeing where ethics can benefit scientific endeavours. However, it remains to answer the question of the ethics of the relationship between science and its object of study, Nature.

Therefore, the idea of nature and the impact it has on the aims and objectives of science could also be a good subject matter for philosophy, the presuppositions of the science of nature as stable and malleable, to study and methods of science that find the further extension in the application of its knowledge, sometimes called applied science can be philosophically questioned. One must remember here that moral questions about the facts of science are not being asked here but the reason why those questions are asked as opposed to other questions is significant. Said with a simple example, one is not asking for the ethical judgement of the boiling point or freezing point of water, but asking why scientists are interested in the boiling or freezing point of water say instead of studying what exactly makes the taste of water different for people in different water bodies. Both these topics are studied but the questions of the first kind are more emphasized and more "factual." Biology would be interested in the second question, so sometimes it is called a soft science, this division indicating that there seems to be a hidden hierarchy of what is more factual and less factual. Which in some sense then is an opinion on scientific facts, which ideally are not subject to judgements of values. 
With increasing ecological damage to the environment, one must consider that historically science has been directed towards nature as a means of controlling nature or taming nature. The facts of science allow the extraction of resources from nature and putting these resources into human use.

Sarukkai (2012, p. 25) points out “... science is not just another story, another narrative, about the universe; it is also one that establishes control over it." In other words, he opines that the capacity of science to intervene in the natural world is unmatched by other disciplines, science manipulates nature. There are examples of this intervention everywhere - chemical processes to produce new forms of compounds that resulted in the invention of plastics. Understanding Hydrocarbons resulted in the proliferation of the petroleum industry. Advances in agricultural sciences and understanding the processes in growing plants has led to widespread development of agriculture in places that agriculture was not possible. Development of cash crops and other soil technologies also have focused on maximizing benefit and minimising input.

All this sounds amazing until one looks back at the devastation to the natural world and nonhuman nature that has been caused. It is unfair to say that science is responsible for the destruction of the environment. But one can say that science has been so focused on observing nature for exploitation and its manipulation that it has not paid attention to those studies which may benefit the preservation and conservation of the natural world. I am not saying no scientists are working on nature, but most of science functions from this earlier presupposition.

Biological sciences, particularly ecologists and sustainability scientists have taken on the lonesome task of restoring nature. The rest of the scientific community be it physics, or technology prefers a hands-off approach towards the restoration of the environment. This is perhaps because some scientists believethemselves to be of the world but not in it.

This the superstition of science, one that seems to see knowledge as unembedded in the world that produces it. Science is and has been 
concerned historically with relating to nature in a particular way. This has always been a relationship of dominance where science puts nature to use, the knowledge produced by science is used to prepare nature for human use. This utilitarian perspective of science has been critiqued by ecofeminist and environmental philosophers. This is the domain of science that should be subjected to the moral compass by both philosophy and social sciences. It is the need for these disciplines to challenge science to change the way it relates to nature. Disciplines such as Biological sciences followed by medicine have been one of the first few disciplines to bring in ethics of research, particularly because the intervention of scientific methods of study of sentient beings and life is most visible as dangerous.

\section{Conclusion}

Therefore the question must not be one of 'understanding' for the utilisation of nature, but the utilisation of science for nature. Science must begin to serve nature and its preservation, not the other way around. Nature has served as a sterile object of scientific research, a passive recipient of manipulation. If science does not correct this balance soon, we as humans will find ourselves without a habitable environment. And one cannot also eat scientific facts; however true they may be. If science honours facts and truth, it is important for scientists to also admit the truth about its aims and function in society.

The ethical questions which arise when applied science collides with traditional belief systems such as religion or cultural traditions is one of the issues that arises because science places itself apart from the society that sustains and cohabits it. For instance, using an animal protein within a rice plant to increase vitamin $\mathrm{A}$ in the grain may seem like a very good nutritional solution, on the other hand, many strict vegans and vegetarians such as the Jains may feel very uncomfortable with this scientific advancement. That is because ethical perspectives are also given from within some of these social religious frameworks of communities. 
When questions of such moral responsibility arise, the ethical domain must uniquely enter the domain of science. Numerous questions such as - what kind of knowledge must be sought? Is the seeking of facts about certain things in the world dangerous? Who should control these facts? Are the scientific facts public knowledge or are they to be maintained by the people who funded the research? Can the scientific facts be used for secretive control or political blackmail by either withholding or disseminating information? Is scientific knowledge public? If yes, then should the production, dissemination, and sharing of that knowledge be regulated by democratic processes? These are issues that should be addressed by both the scientist and the people who benefit from science.

The image of a lonely male scientist in a lab working on great discoveries continues to be a stereotype in these disciplines. The scientific hero has replaced the religious icon. When the actual source for production of scientific knowledge is searched for, it is found that science is done in institutions, in clusters of communities, and scientific knowledge is funded by governments and corporates. The science itself is considered universal knowledge for the good of humanity, the control of scientific knowledge is mired in social economic and political structures of society. Thus, it can be seen that increased economic benefits are interfering in the true pursuit of scientific knowledge. It is well known that designing for obsolescence is a common practice in the development of new technologies.

On the other hand, certain kinds of basic science research have little credibility while more beneficial and charismatic science is given priority. Charismatic science can create scientific myths and showcase science as a useful and magical enterprise to the general public. Much like the scientific shows of the early 19 century, these charismatic scientific discoveries are not innocent. This kind of propaganda may benefit a few instances for funding, but the unbalanced development of scientific studies is likely to harm the true and ethical purpose of science and the benefits for human society in the long run. It is perhaps much more exciting to talk and write about the glamour of walking on the surface of the moon or 
searching for water in distant planets and do the science required for it rather than work on a nutritive potato resistant to drought for those dying of hunger. It is more economically beneficial to invest in developing new forms of plastic then working out the science to clean up our air and water. This lopsided pursuit of science is not the fault of science as a discipline but of the socio-economic circumstances that have crept into the domain of scientific knowledge production. It is therefore important for us as philosophers to ask of science those ethical and moral questions which have not been asked strongly. At the same time, it is also important for us to support the pursuit of truth as the common aims of both philosophy and science. One must urge for a coming of a value-driven science, whose aims take into account the state of the planet and its people today. Knowledge generated that addresses the survival of humanity itself, not socio-economic welfare would be the need of the hour. Science can be useful, but to whom and where this use is employed must be the concern of philosophers and scientists must work with them as a community.

\section{Acknowledgement}

I am extremely grateful to Dr Sundar Sarukkai for some of the perspectives his ideas have provided for me in this subject. Many ideas presented here are the result of his reflections and our conversations on the same. This paper is a post- reflection on his views on the nature of Science and Society.

\section{References}

Merchant, C. (2005). Radical ecology. Routledge.

Sayer, A. (2011). Why things matter to people: social science, values and ethical life. Cambridge: Cambridge University Press.

Sarukkai, S. (2012). What is Science? National Book Trust: India.

i Induction heating is the process of heating an electrically conducting object (usually a metal) by electromagnetic induction, through heat generated in the object by eddy currents. 